\title{
Palatal Mucoperiosteal Island Flaps for Palate Reconstruction
}

\author{
Hong Youl Kim, \\ Jin Hwang, \\ Won Jai Lee, \\ Tai Suk Roh, \\ Dae Hyun Lew, \\ In Sik Yun
}

\section{Department of Plastic and Reconstructive Surgery, Institute for Human Tissue Restoration, Yonsei University College of} Medicine, Seoul, Korea

No potential conflict of interest relevant to this article was reported.
Background: Many options are available to cover a palatal defect, including local or free flaps. The objective of this study was to evaluate the usefulness of palatal mucoperiosteal island flap in covering a palatal defect after tumor excision.

Methods: Between October 2006 and July 2013, we identified 19 patients who underwent palatal reconstruction using a palatal mucoperiosteal island flap after tumor excision. All cases were retrospectively analyzed by defect location, size, tumor pathology, type of reconstruction, and functional outcomes. Speech and swallowing functions were evaluated using a 7-point visual analog scale (VAS) score.

Results: Among the 19 patients, there were 7 men and 12 women with an age range of 25 to 74 years (mean, $52.5 \pm 14.3$ years). The size of flaps was $2-16 \mathrm{~cm}^{2}$ (mean, $9.4 \pm 4.2 \mathrm{~cm}^{2}$ ). Either unilateral or bilateral palatal island flaps were used depending on the size of defect. During the follow-up period (mean, 32.7 \pm 21.4 months), four patients developed a temporary oronasal fistula, which healed without subsequent operative. The donor sites were well re-epithelized. Speech and swallowing function scores were $6.63 \pm 0.5$ and $6.58 \pm 0.69$ on the 7-point VAS, indicating the ability to eat solid foods and communicate verbally without significant disability.

Conclusion: The palatal mucoperiosteal island flap is a good reconstruction modality for palatal defects if used under appropriate indications. The complication rates and donor site morbidity are low, with good functional outcomes.

Keywords: Palate / Neoplasms / Surgical flaps

\section{INTRODUCTION}

Post-ablation palatal reconstruction has been a very challenging operation. The soft palate is responsible for closing off the nasal passage and airway. It is not easy to restore associated swallowing and speech functions and reconstruct the defect using a "like tissue", while reduce donor site morbidity. Many techniques including the tongue flap, buccal mucosal flap, forehead flap, the temporalis, the mucoperiosteal island flap, and the fasciocutaneous free flap have been introduced to reconstruct oral defects [1-3].

\section{Correspondence: In Sik Yun}

Department of Plastic and Reconstructive Surgery, Gangnam Severance Hospital, Yonsei University College of Medicine, 211 Eonju-ro, Gangnam-gu, Seoul 135-720, Korea

E-mail: eqatom@yuhs.ac

Received June 28, 2014 / Revised July 29, 2014 / Accepted August 5, 2014
The palatal reconstruction with a mucoperiosteal island flap was first described by Gullane and Arena [3] in 1977. The usefulness of this method has been demonstrated in many studies, with low postoperative complication rates and low donor-site morbidity [4-6]. However, few studies have mentioned functional outcomes following this method, as most of the results have been subjective observation [4]. Thus, the objective of this study was to evaluate the usefulness the mucoperiosteal island flap after a tumor ablative of the palate.

\section{METHODS}

We identified 19 patients who underwent palatal reconstruction between October 2006 and July 2013 using either unilateral or bilateral palatal mucoperiosteal island flaps after tumor excision at

70 Copyright $\odot 2014$ The Korean Cleft Palate-Craniofacial Association 
the Severance Hospital (Seoul, Korea). The medical record for each case was reviewed for defect location, defect size, pathology report of the tumor, type of reconstruction and functional outcomes. Speech and swallowing functions had been evaluated at every out-patient clinic visit. Patients were asked how they were eating and whether there was any current problem with swallowing. Speech intelligibility was also evaluated by how others recognized each patient's speech during routine conversation. The final highest score was recorded among repeatedly checked scores during the follow-up period. Speech and swallowing functions were evaluated with a 7-point visual analog scale (VAS) score at the last out-patient clinic follow-up visit (Table 1) [7].

\section{Surgical technique}

After complete extirpation of tumor lesion, the flap was designed to be much bigger than the defect itself depending on operator's experience, and the hard palate was infiltrated using $1 \%$ Xylocaine with epinephrine 1:100,000 in a subperiosteal plane. An incision was made along the alveolar ridge with a No. 15 blade, $2-5 \mathrm{~mm}$ away from the dentition to a length appropriate for the defect size. The flap was elevated with a freer elevator. Bleeding from perforating branches was electrocauterized, being careful not to injury the great palatine artery. The flap was rotated into the defect and inset with absorbable sutures. If a defect size was too large to be reconstructed by a unilateral mucoperiosteal flap, a flap from the contralateral side was mobilized for the remainder of the uncovered surface. It was not necessary to cover the bone-exposed donor site, as the mucosal epithelium covered the surface within 3 months $[5,6]$.

\section{RESULTS}

Among the 19 patients, there were 7 male and 12 female patients with a mean age of 53.6 \pm 14.4 years (range, $25-74$ years). The extent of tissue defect was soft-palate only in 10 patients, hard-palate only in 4 patients, and soft and hard palate in 5 patients. The size of flaps was $2-16 \mathrm{~cm}^{2}$ (mean, $9.4 \pm 4.2 \mathrm{~cm}^{2}$ ). The unilateral palatal island flaps were used in 15 cases (Fig. 1), including three cases in which the flaps were combined with either a pharyngeal flap or an AlloDerm(LifeCell, Branchburgh, NJ, USA) graft. In a single case, AlloDerm was used to cover the nasal side defect. Bilateral flaps were used to cover rather large defects in four cases (Fig. 2).

Squamous cell carcinoma was the most common diagnosis in the final pathological report $(\mathrm{n}=8)$. The flaps survived and healed completely without complications. The donor sites became well re-epithelized during the follow up period. Speech and swallowing function VAS scores were $6.63 \pm 0.5$ and $6.57 \pm 0.69$ (Table 2). There were 2 case of hypernasality among the 19 patients.

During the follow-up period (range, 11-80 months; mean, 34.9 \pm 21.5 months), only four patients developed a postoperative oronasal fistula, including one patient who required additional radiotherapy. All four of these oronasal fistulas healed without subsequent operative intervention.

\section{DISCUSSION}

Reconstruction of oral cavity defects continues to advance. The surgeon is presented with a wide variety of options, both local and free flap varieties. Techniques previously associated with signifi-

Table 1. Visual analog scale

\begin{tabular}{lcl}
\hline Swallowing difficulty & Score & \multicolumn{1}{c}{ Speech intelligibility } \\
\hline $\begin{array}{l}\text { Patients without swallowing impairment } \\
\text { Discomfort during consumption of a solid diet }\end{array}$ & 7 & Can speak without errors \\
\hline $\begin{array}{l}\text { Consumption of a solid diet was feasible, but water should be } \\
\text { swallowed simultaneously }\end{array}$ & 5 & Occasional errors \\
\hline Only a soft diet was possible & 4 & Intelligible but noticeably in error \\
\hline Discomfort with a soft diet & 3 & Can speak intelligibly with careful listening \\
\hline Could consume a liquid diet & 4 & Comprehensive by repetitive speaking \\
\hline Unable to consume any form of diet & 2 & Those whose speech was usually unintelligible \\
\hline
\end{tabular}



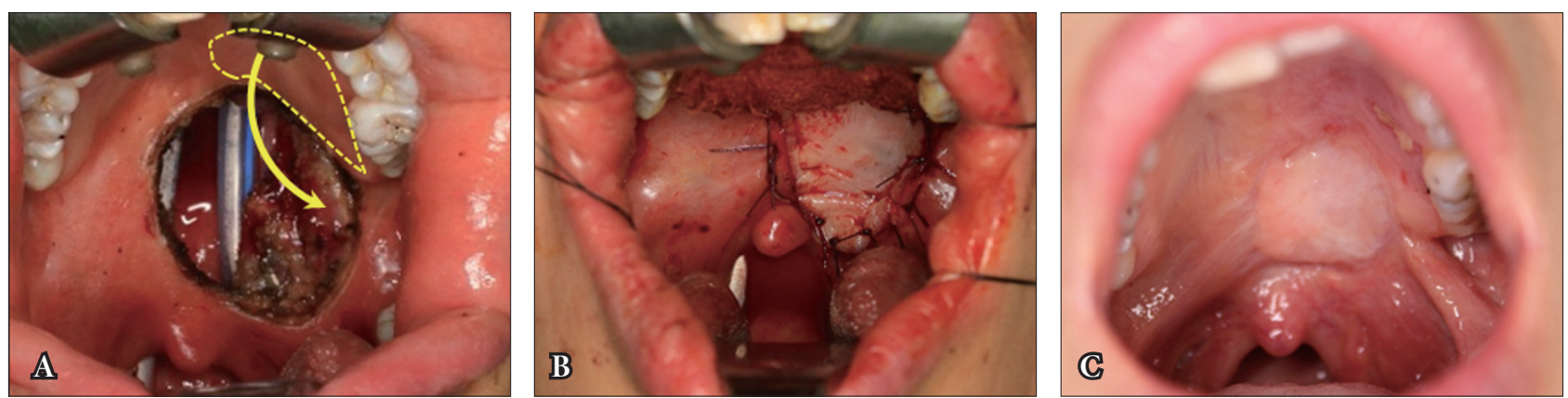

D
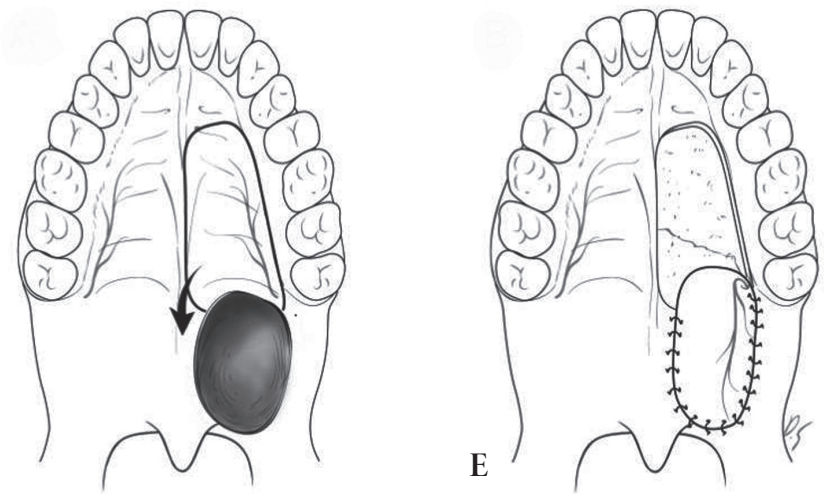

Fig. 1. A 44-year-old woman (patient No. 7) who underwent unilateral palatal mucoperiosteal flap to cover the $3 \times 2 \mathrm{~cm}$ sized palatal defect. (A) Photographs after tumor excision, (B) after reconstruction, and (C) 4 weeks after operation. (D, E) Schematic drawing of the flap procedure. Arrow means direction of rotation of the mucoperioeteal flap.
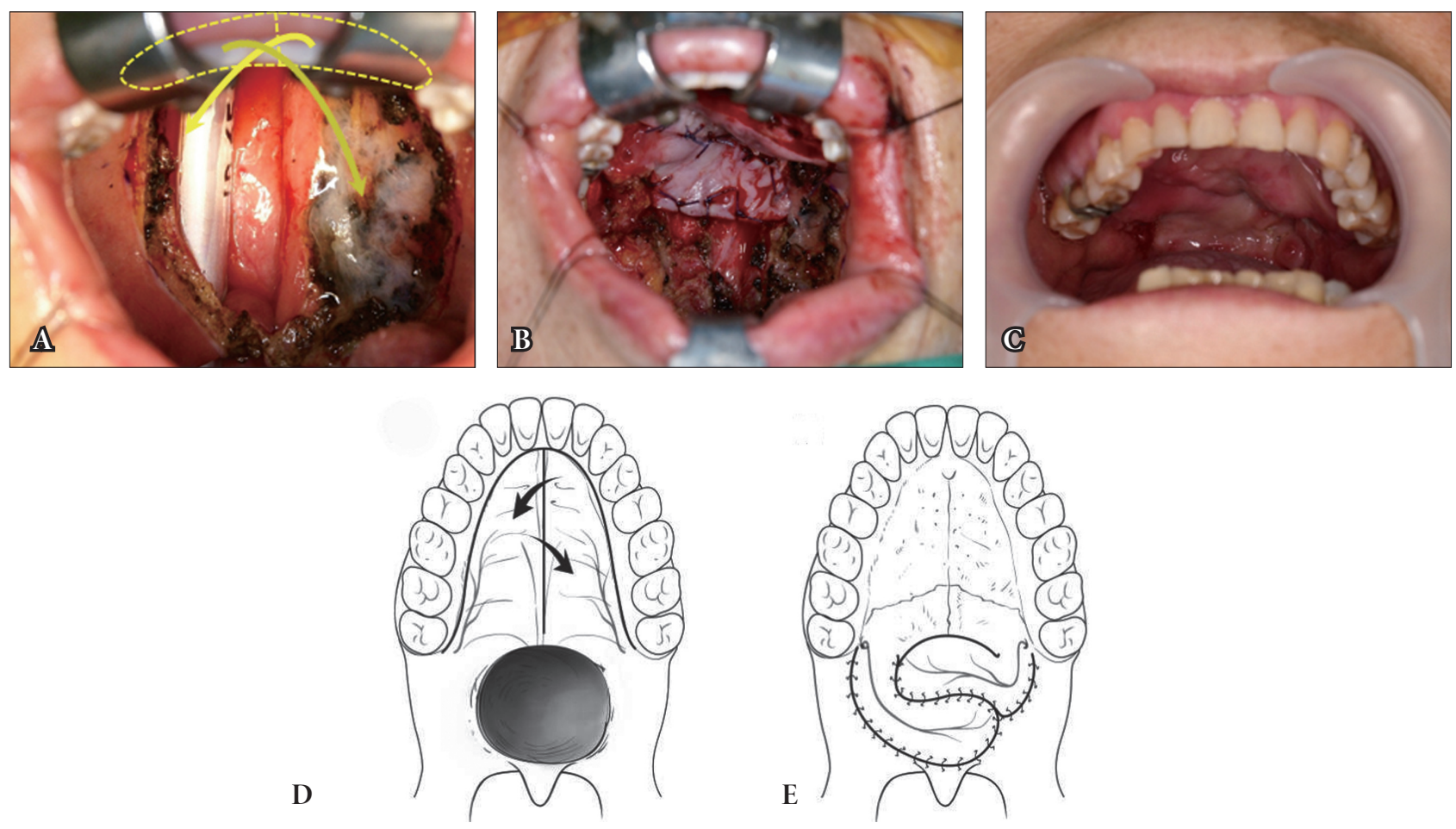

Fig. 2. A 71-year-old woman (patient No. 12) who underwent bilateral palatal mucoperiosteal flap to cover the $4 \times 4 \mathrm{~cm}$ sized palatal defect. (A) Photographs after tumor excision, after reconstruction (B), and 4 weeks after operation (C). (D, E) Schematic drawing of the flap procedure. Arrow means direction of rotation of the mucoperioeteal flap. 
Table 2. Patient demographics

\begin{tabular}{|c|c|c|c|c|c|c|c|c|}
\hline No. & Age/Sex & Defect location & Pathology & $\begin{array}{l}\text { Defect size } \\
\left(\mathrm{cm}^{2}\right)\end{array}$ & Reconstruction methods & $\begin{array}{l}\text { Follow-up } \\
\text { period }\end{array}$ & Sp. & Sw. \\
\hline 1 & $45 / F$ & Hard palate & Pleomorphic adenoma & $4 \times 2$ & Unilateral PMPF & 80 & 7 & 7 \\
\hline 2 & $30 / F$ & Hard palate & Adenoid cystic carcinoma & $3 \times 2$ & Unilateral PMPF & 67 & 7 & 7 \\
\hline 3 & $50 / \mathrm{M}$ & Soft palate & Squamous cell carcinoma & $2 \times 2$ & Unilateral PMPF \& pharyngeal flap & 58 & 7 & 5 \\
\hline 4 & $74 / \mathrm{M}$ & Soft palate & Squamous cell carcinoma & $4 \times 3$ & Unilateral PMPF \& pharyngeal flap & 55 & 6 & 6 \\
\hline 5 & $45 / F$ & Soft \& hard palate & Mucoepidermoid carcinoma & $4 \times 3$ & Unilateral PMPF & 46 & 6 & 6 \\
\hline 6 & $37 / M$ & Soft \& hard palate & Mucoepidermoid carcinoma & $4 \times 3$ & Unilateral PMPF & 49 & 7 & 7 \\
\hline 7 & $44 / F$ & Soft palate & Mucoepidermoid carcinoma & $3 \times 2$ & Unilateral PMPF & 42 & 6 & 7 \\
\hline 8 & $60 / \mathrm{M}$ & Hard palate & Squamous cell carcinoma & $3 \times 3$ & Unilateral PMPF & 39 & 6 & 6 \\
\hline 9 & $55 / F$ & Hard palate & Adenoid cystic carcinoma & $2 \times 1$ & Unilateral PMPF \& Alloderm graft & 32 & 6 & 5 \\
\hline 10 & $66 / \mathrm{M}$ & Soft palate & Squamous cell carcinoma & $2 \times 3$ & Unilateral PMPF & 13 & 7 & 7 \\
\hline 11 & $64 / F$ & Soft \& hard palate & Mucoepidermoid carcinoma & $4 \times 4$ & Unilateral PMPF & 19 & 7 & 7 \\
\hline 12 & $71 / F$ & Soft palate & Squamous cell carcinoma & $4 \times 4$ & Bilateral PMPF & 17 & 6 & 7 \\
\hline 13 & $56 / F$ & Soft palate & Mucoepidermoid carcinoma & $3 \times 3$ & Unilateral PMPF & 21 & 7 & 6 \\
\hline 14 & $55 / F$ & Soft palate & Mucoepidermoid carcinoma & $4 \times 4$ & Bilateral PMPF & 17 & 7 & 7 \\
\hline 15 & $71 / F$ & Soft palate & Adenoid cystic carcinoma & $3 \times 2$ & Unilateral PMPF & 12 & 7 & 7 \\
\hline 16 & $63 / \mathrm{M}$ & Soft \& hard palate & Squamous cell carcinoma & $3 \times 3$ & Unilateral PMPF & 11 & 7 & 7 \\
\hline 17 & $25 / F$ & Soft palate & Adenocarcinoma & $3 \times 3$ & Unilateral PMPF & 16 & 7 & 7 \\
\hline 18 & $34 / F$ & Soft \& hard palate & Squamous cell carcinoma & $6 \times 6$ & Bilateral PMPF \& buccal mucal flap & 13 & 7 & 7 \\
\hline 19 & $53 / \mathrm{M}$ & Soft palate & Squamous cell carcinoma & $3 \times 2$ & Bilateral PMPF & 15 & 6 & 7 \\
\hline
\end{tabular}

Follow-up period are measured by months.

Sp., speech visual analog scale score; Sw., swallowing visual analog scale score; F, female; PMPF, palatal mucoperiosteal flap; M, male.

cant morbidity, such as tongue flaps and intraoral forehead and intraoral galea flaps, may no longer be required for many palatal and retromolar defects. Free flaps, such as radial forearm and anterolateral thigh free flaps, have increased possibilities for reconstruction. Nevertheless, free tissue transfers are best reserved for the most complex and/or the largest of oral cavity defects [8].

The mucoperiosteal island flap was introduced by Millard [9] in 1962 to lengthening the palate in cleft patients. However, high complication rates with mid-facial deformities and malocclusion made it less than popular at the time. Since palatal reconstruction with mucoperiosteal island flap was first described by Gullane and Arena [3] in 1977, the usefulness of this method has been reported in many studies. The anatomical basis of the palatal mucoperiosteal island flap was established by Maher's [10] angiographic study, according to which the mucoperiosteal island flap mainly relies on the great palatine artery from the descending palatine artery. The sensory nerve exits through the greater palatine foramen with the great palatine artery, and the neurovascular bundle travels along the lateral aspect of transverse suture line. This enables sensory reconstruction with a palatal mucoperiosteal island flap.

The goals of palatal reconstruction are to separate the oral and nasal cavities and to restore physiological nasal breathing, swallowing, and speech. Multiple options have been developed to decrease donor site morbidity, such as the tongue flap, forehead flap, mucoperiosteal island flap, buccal mucosal flap, and fasciocutaneous free flap [1-3]. In early days, we reconstructed the nasal surface using pharyngeal flap, but afterward, we reconstructed only oral side because there was no functional problem in only oral side reconstruction patients.

The merit of mucoperiosteal island flap is that it has a blood supply based on the great palatine artery, which affords a wide arc of rotation to be applied to any area within the oronasal cavity with flap sizes up to $16.5 \mathrm{~cm}^{2}$. It is an excellent composite flap and can be used to successfully restore an oronasal defect without two layer 
closure. For extremely large defect, the flaps can elevated bilaterally, as was the case in four of our patients [5,6]. Use of palatal tissue is unique in its ability to limit donor site morbidity. Denuded palatal tissue heals through secondary intention, with resultant mucosa almost identical to the previous tissue with a certain amount of reinnervation of the new tissue [8]. All of our cases showed complete healing of the donor sites without any complications. The exposed palatal bone at the donor site does not have to be covered and will re-epithelialize with mucosa within 3 months. A shorter operation time and decreased technical challenges are other advantages over free flaps, which reduce complications with general anesthesia.

Speech and swallowing function scores were $6.64 \pm 0.49$ and $6.52 \pm 0.71$, respectively, indicating that patients could have a solid diet and communicate verbally without significant problems. Speech was evaluated during patient interviews, where a second physician was present for this purpose. Swallowing function was evaluated by listing actual diet items. This objective result emphasizes the usefulness of the mucoperiosteal island flap. Two patients were found to have hypernasality, but these patient did not feel additional operations to be necessary. Keuning et al. [11] reported that flap rotation of the posterior pharyngeal wall for reconstructing the soft palate presents a favorable nasal resonance in $88 \%$ of cases. In a functional analysis of 45 consecutive patients, Lv et al. [12] concluded that the size of defect, rather than the type of flap, will have the most critical influence on soft palate postoperative function following reconstruction. These results indicated no significant difference in functional outcomes between free flaps and mucoperiosteal island flaps.

The limitation of our study was that we did not conduct videofluoroscopy for a more objective speech outcome. Our study did not compare of speech and swallowing functions against outcomes following free flap recontructions. However, the speech and swallowing function scores of our patients were considerably high. Our study is meaning when considering the high success rate, zero flap failure, and a relatively large number study subjects. The functional aspect of mucoperiosteal island flap was evaluated more objectively by using a VAS scoring system. It will be important to reach a consensus regarding the proper indications palatal defects for operations which maintain the highest quality of life for patients who undergo palatal surgery.

In conclusion, palatal mucoperiosteal island flap is a good reconstructive option for post-excision palatal reconstruction. It is able to cover a wide variety of defect locations and sizes and provides acceptable postoperative functional outcomes with minimal complications.

\section{ACKNOWLEDGMENTS}

The authors would like to thank Dong-Su Jang, MFA, (Medical Illustrator, Seoul, Korea) for his help with the illustrations.

\section{REFERENCES}

1. Komisar A, Lawson W. A compendium of intraoral flaps. Head Neck Surg 1985;8:91-9.

2. Muller RN, Sprugel DG, Wayman CW, Bartelt GE, Bobula CM. Behavior and transport of industrially derived plutonium in the Great Miami River, Ohio. Health Phys 1977;33:411-6.

3. Gullane PJ, Arena S. Palatal island flap for reconstruction of oral defects. Arch Otolaryngol 1977;103:598-9.

4. Moore BA, Magdy E, Netterville JL, Burkey BB. Palatal reconstruction with the palatal island flap. Laryngoscope 2003;113:946-51.

5. Genden EM, Lee BB, Urken ML. The palatal island flap for reconstruction of palatal and retromolar trigone defects revisited. Arch Otolaryngol Head Neck Surg 2001;127:837-41.

6. Magdy EA. The palatal island mucoperiosteal flap for primary intraoral reconstruction following tumor ablative surgery. Eur Arch Otorhinolaryngol 2011;268:1633-8.

7. Yun IS, Lee DW, Lee WJ, Lew DH, Choi EC, Rah DK. Correlation of neotongue volume changes with functional outcomes after long-term follow-up of total glossectomy. J Craniofac Surg 2010;21:111-6.

8. Ward BB. The palatal flap. Oral Maxillofac Surg Clin North Am 2003;15:467-73

9. Millard DR Jr. Wide and/or short cleft palate. Plast Reconstr Surg Transplant Bull 1962;29:40-57.

10. Maher WP. Distribution of palatal and other arteries in cleft and noncleft human palates. Cleft Palate J 1977;14:1-12.

11. Keuning KH, Meijer GJ, van der Bilt A, Koole R. Revisional surgery following the superiorly based posterior pharyngeal wall flap. Historical perspectives and current considerations. Int J Oral Maxillofac Surg 2009;38:1137-42

12. Lv M, Shen Y, Li J, Zhang C, Zhu H, Sun J. Immediate reconstruction of soft palate defects after ablative surgery and evaluation of postoperative function: an analysis of 45 consecutive patients. J Oral Maxillofac Surg 2014;72:1397-406. 